\title{
Wetland Modeling in PCSWMM: Exploring Options to Define Wetland Features and Incorporate Groundwater Exchanges
}

\author{
Caroline Charbonneau ${ }^{1}$ and Andrea Bradford ${ }^{2}$ \\ ${ }^{1}$ Walter Fedy, Kitchener, Ontario; ${ }^{2}$ University of Guelph, Guelph, Ontario
}

\begin{abstract}
Wetlands in Southern Ontario are experiencing degradation from urban development. Hydrologic analysis is important to demonstrating that a development will not have negative impacts on wetlands. A wetland water balance study has been conducted to develop reference hydrologic regimes for two wetlands in Pickering, Ontario. Knowledge gained from wetland water balance analysis informed the development of PCSWMM models. The objective of this study was to explore options for incorporating and defining wetlands in PCSWMM, select groundwater interaction parameters, and optimize the process for creating a calibrated catchment-wetland model using known seasonal wetland water levels. Continuous monitoring data was used for calibration and validation of the models. Methods, calibration targets, and challenges encountered when defining groundwater interactions and stage-storage relationships will be highlighted. The study will identify areas where increased data collection could improve the model parameterization. The discussion will address the value of a model which can both adequately represent the development and the wetland by incorporating infiltration-runoff effects, evapotranspiration changes, LID practices, groundwater regimes, and dynamic feedbacks between the wetland water level and the system.
\end{abstract}

\section{Introduction}

\subsection{Background}

Wetlands are sensitive ecosystems under significant pressure from land use changes and land and water management practices. In Southern Ontario, they are being negatively impacted by urban development, which increases surface runoff volumes and alters surface and groundwater drainage patterns (Davidson 2014; Snell 1987). Many existing strategies do not sufficiently address the impacts of urbanization on wetlands; human activities and conventional stormwater management are altering the natural regimes of these systems with undesirable ecological responses (e.g. Elliot et al. 2010; Burns et al. 2012; Wagner and Breil 2013). Groundwater dependent ecosystems such as wetlands have experienced negative impacts and degradation from urbanization, resulting in the inability to perform their full range of functions and services within the landscape (Krause et al. 2007). The ability of wetlands to continue to provide critical ecosystem services in areas being urbanized largely depends on our ability to protect their hydrologic regime. Hydrologic modeling is an important tool for predicting changes in the hydrologic response in an urbanizing catchment and the capacity of proposed stormwater management systems to mitigate changes.

The wetland hydroperiod describes the seasonal change in wetland water depth, or its hydrologic signature, which is dependent on the maintenance of water transfer mechanisms into and out of the wetland (Mitsch and Gosselink 2000). Water transfer mechanisms in wetlands include surface water exchanges, groundwater exchanges and evapotranspiration losses, and inputs include precipitation and runoff from the surrounding areas in the form of overland flow pathways (Acreman and Miller 2007). Each of these local wetland interactions and mechanisms must be represented in the model to determine the impacts of urbanization and how they cumulatively affect the wetland's hydroperiod (Carol et al. 2013). The model must be able to provide a reasonable estimate of the wetland hydroperiod as a model output so that pre-development conditions can be compared to post-development conditions, allowing impacts to the wetland's regime to be quantified (Gasca and Ross 2009) and ultimately mitigated. Wetlands have unique attributes and incorporating them into the model often requires simplification. However, care must be taken to avoid oversimplification which may misrepresent crucial interactions and limit the ability to predict alterations to the hydrologic regime.

\subsection{Objectives and Scope}

The overall objective of the study is to develop a dynamic catchment-groundwater-wetland model within the PCSWMM hydrologic model framework as a simulation tool capable of predicting impacts to wetland hydroperiod. PCSWMM's groundwater modeling capabilities will be explored to simulate the catchment, the wetland and subsurface exchanges. Similar to approaches found in literature, development and parameterization of a catchment

Charbonneau, Caroline and Andrea Bradford. 2016. Wetland Modeling in PCSWMM: Exploring Options to Define Wetland Features and

Incorporate Groundwater Exchanges. Journal of Water Management Modeling 25:C411.

https://doi.org/10.14796/JWMM.C411 @ C CHI 2016. www.chijournal.org ISSN 2292-6062. 
model relied on knowledge gained from a water balance analysis and a dataset that included continuous surface and groundwater levels and detailed wetland topography. This paper focuses on options for incorporating the wetland and its groundwater interactions into the model. The model was calibrated and validated using two different approaches for representing groundwater outflow from the wetland.

\section{Methodology}

\subsection{Study Sites}

The study sites for this investigation are two wetlands in the Duffins Creek watershed. The wetlands are located $<1 \mathrm{~km}$ apart, at Sideline 22 and Sideline 26, north of Taunton Road in Pickering, Ontario (Figure 1). Urban growth and expansion will result in both the wetland catchments undergoing development within the next three to ten years.

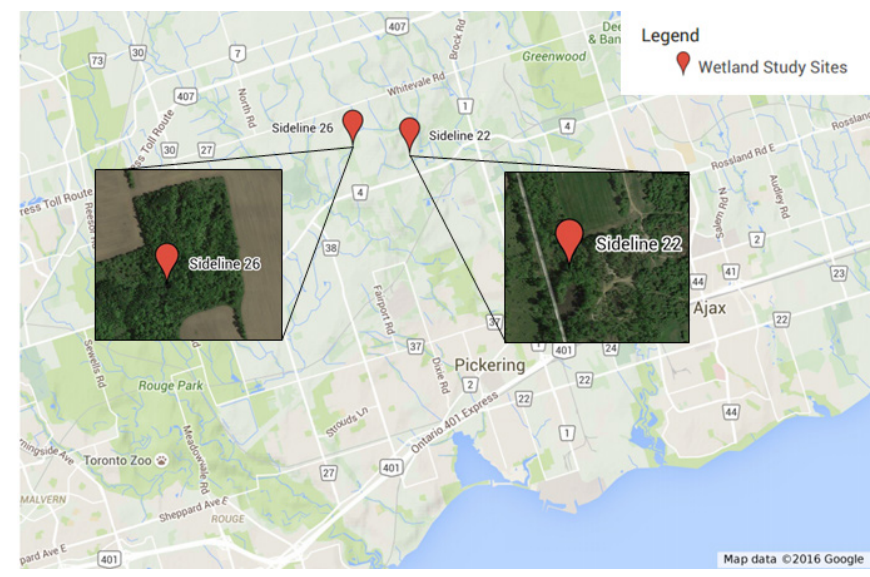

Figure 1 Site location.

This paper focuses on the calibration and validation of a dynamic wetland-catchment-groundwater model for the Sideline 22 study site. The conceptualization of the interactions at Sideline 22 highlighted the need for a more detailed incorporation of a groundwater outflow and once developed, the methods will be applied to Sideline 26.

\subsection{Available Data}

The wetlands have been monitored by the Toronto Region Conservation Authority (TRCA) since 2013. Data provided by TRCA for the purpose of this study include:

- continuous precipitation, temperature, groundwater and surface water levels;

- detailed topographic surveys of the wetland basins and stage-storage relationships; and

- results of slug tests and borehole samples.

This study relies on data from a three season gauge at the Brockwest landfill site, $\sim 3 \mathrm{~km}$ southeast of the site, for periods of 2013-06 to 2013-11 and 2014-04 to 2014-11 The Brockwest gauge was upgraded to a heated four season rain gauge in the fall of 2014 to support year round modeling and analysis in the future.

General groundwater flow directions and historical spot measurements of groundwater levels were obtained from consulting reports for the surrounding area undergoing development. Water levels within the wetlands are available at stations installed for an ecohydrological study (Figure 2). Each station consisted of surface water, $1 \mathrm{~m}$ deep, and $2 \mathrm{~m}$ deep groundwater monitors equipped with Schlumberger Model D1501 mini-divers. Sideline 22 had two stations within the wetland, located $30 \mathrm{~m}$ apart. In addition, 2 m deep groundwater piezometers were installed approximately $200 \mathrm{~m}$ to the east and south-east. Continuous water level data is available at $15 \mathrm{~min}$ intervals for the periods of 2013-06 to 2013-11 and 2014-04 to 2014-11.

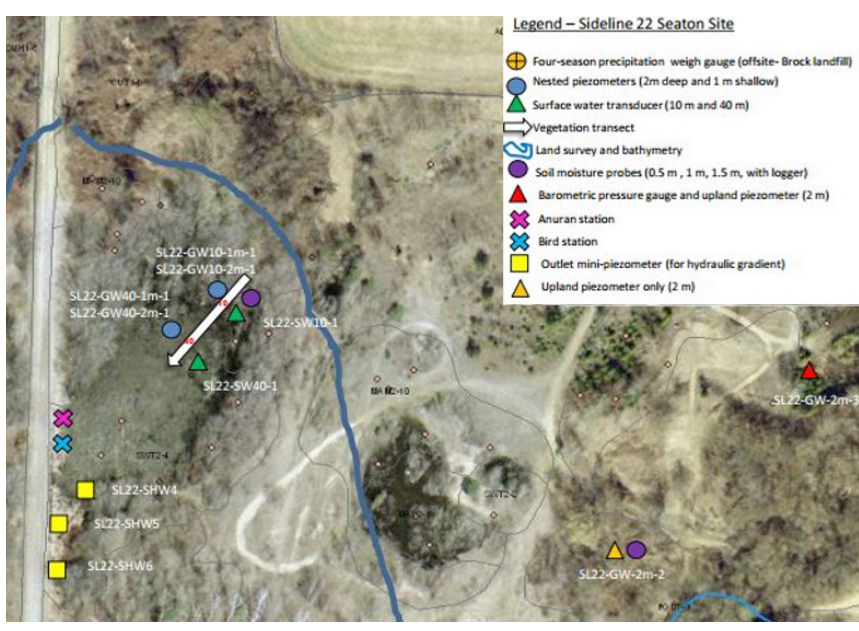

Figure 2 Monitoring locations (TRCA 2013).

TRCA provided detailed survey data for the wetlands. The surveying was completed over $2 \mathrm{~d}$ in 2013-01 at Sideline 22. TRCA also carried out slug tests in 2015-01 and provided estimates of the hydraulic conductivity of the deposits underlying the wetlands.

\subsection{Model Approach}

PCSWMM was used to model the wetlands and their catchments. The approach was to begin with a simple catchment system and increase the level of complexity necessary to define all the known interactions in the wetland and achieve calibration. The 2013 data set was used for calibration and the 2014 data set used for validation.

\section{Model Setup}

The wetland subcatchments incorporated into the PCSWMM model were delineated based on topographic information from GIS maps provided by TRCA (TRCA 2014). The GIS information helped to identify slopes and land use types. Soil properties were obtained through borehole information from wetland samples 
and from catchment monitoring (TRCA 2013; Sernas Associates 2013). Subcatchment parameterization for Sideline 22 is summarized in Table 1.

Table 1 Subcatchment properties.

\begin{tabular}{lcc}
\hline & SC1 & SC2 \\
\hline Land use & Agricultural & Agricultural \\
Area (ha) & 13.03 & 6.73 \\
Width (m) & 857 & 442 \\
Flow length (m) & 152 & 152 \\
Slope (\%) & 10 & 3 \\
Percent impervious (\%) & 3.5 & 3.5 \\
Manning's $n$ - impervious (-) & 0.01 & 0.01 \\
Manning's $n$ - pervious & 0.35 & 0.35 \\
Depression storage impervious area (mm) & 1.3 & 1.3 \\
Depression storage pervious area (mm) & 6.85 & 6.85 \\
Infiltration method & Green-Ampt & Green-Ampt \\
Soils & Loam & Loam \\
Soil capillary suction head (mm) & 90 & 90 \\
Soil saturated hydraulic conductivity (mm/h) & 5 & 5 \\
Initial soil moisture deficit (-) & 0.5 & 0.5 \\
\hline
\end{tabular}

Adding the wetland required defining a feature which could adequately include storage relationships, subsurface losses, and surface and groundwater interactions. Ultimately, the wetland was incorporated as a storage unit because of the capacity in PCSWMM to define a stage-storage relationship.

Hydraulic conductivity estimates were used to estimate seepage parameters. The soils underlying the wetlands were found to have low hydraulic conductivity in the field and the seepage parameters selected for the wetland storage unit was representative of these characteristics.

Detailed wetland topography is required to quantify the relationship between the water level change and the resulting change in storage. To account for storage changes in the bank and subsurface zone, the storage relationship in the wetland was extended below the base of ponding as defined by the topographic study to the lowest observed groundwater elevation. Specific yield must be defined to estimate storage relationships (Hill and Durchholz 2015). Different estimates of specific yield for the bank areas and the subsurface wetland soils were selected (Gasca and Ross 2009), and using these estimates the storage relationship could be extended to the banks and subsurface zones. Figure 3 shows the areas that were considered for each stage. Equations 3 through 5 describe the total volumetric storage calculation for each stage in the wetland.

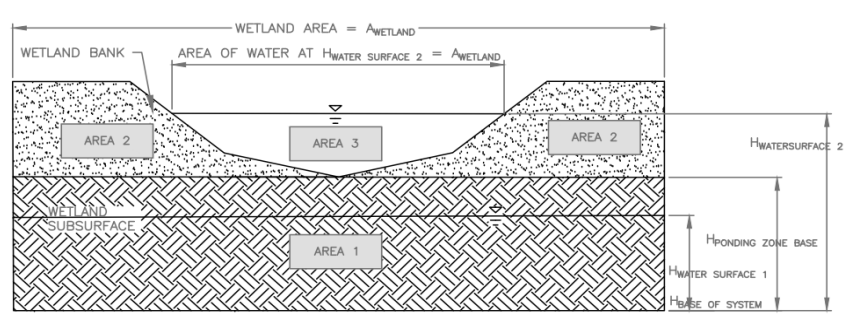

Figure 3 Specific yield estimates.

\section{Scenario 1}

Water level is below base of ponding zone:

$$
\text { Volume }=V_{\text {Areal }}
$$

\section{Scenario 2}

Water level is above the base of the ponding zone:

$$
\text { Volume }=V_{\text {Area1 }}+V_{\text {Area2 }}+V_{\text {Area3 }}
$$

where:

$$
\begin{aligned}
& V_{\text {Areal }}=\left(A_{\text {wetland }}\right) \cdot\left(h_{\text {water surface } 1}-h_{\text {base of system }}\right) \cdot\left(S_{y, \text { subsurface }}\right) \\
& V_{\text {Area } 2}=\left(A_{\text {wetland }}-A_{\text {water surface }}\right) . \\
& \quad\left(h_{\text {water surface2 }}-h_{\text {ponding zone base }}\right) \cdot\left(S_{y, \text { banks }}\right) \\
& V_{\text {Area3 }}=\text { based on surveyed data }
\end{aligned}
$$

A single aquifer was defined for the two contributing catchment areas. The underlying soils in the area informed the choice of parameters for the aquifer. Where known or typical ranges of parameters were reported, the value best suited for the catchment properties was selected. Table 2 summarizes the aquifer parameters and the sources for chosen values when required.

Table 2 Aquifer properties.

\begin{tabular}{lc}
\hline & Aquifer Properties \\
\hline Soil type & Silt loam (low range) \\
Porosity (-) & 0.58 \\
Wilting point (-) & 0.17 \\
Field capacity (-0 & 0.34 \\
Conductivity (mm/h) & 7.62 \\
Conductivity slope (-) & 8.00 \\
Tension slope (-) & 0.00 \\
Upper evap. fraction (-) & 0.50 \\
Lower evap. depth (m) & 6.20 \\
Lower GW loss fraction (-) & 0.002 \\
Bottom elevation (m) & 140.00 \\
Water table elevation (m) & 154.00 \\
Unsaturated zone moisture content (-) & 0.30 \\
\hline
\end{tabular}

Groundwater was defined below each of the contributing subcatchments. The wetland storage unit was assigned as the receiving feature for each subcatchment. Initial groundwater 
elevation was defined based on monitoring results from the report by Sernas Associates (2013).

\section{Calibration}

Figure 4 shows the calibration procedure for the simulation.

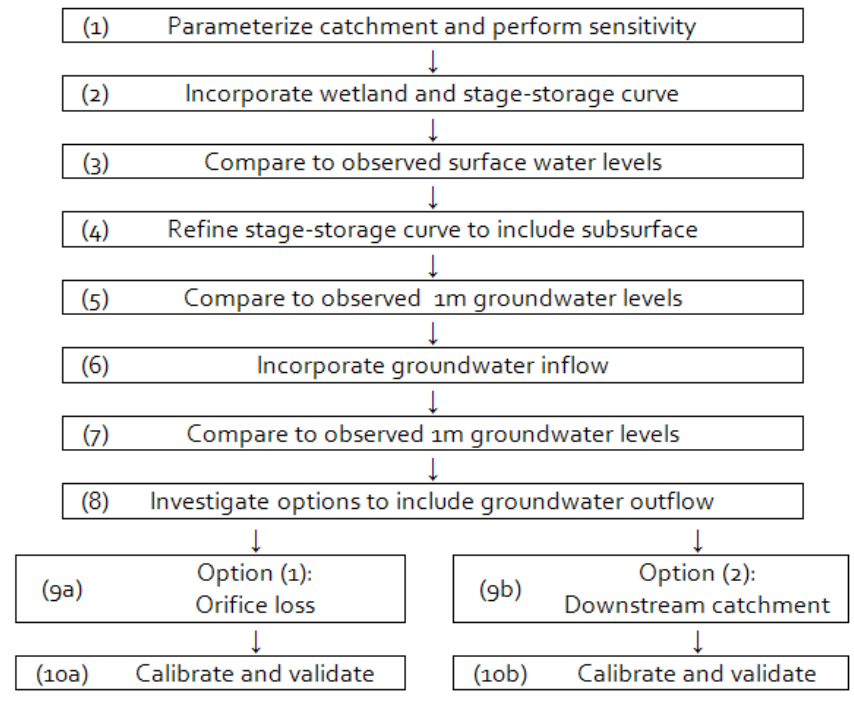

Figure 4 Calibration process.

Parameterization of the catchment was completed based on known catchment characteristics and land use. The sensitivity analysis of the catchment parameters revealed that the volume of runoff from the catchment to the wetland was most sensitive to depth of depression storage, flow length and Manning's $n$ for impervious surface. The wetland conceptualization developed from the water balance did not find runoff to be a significant contribution to the wetland water level. The sensitivity analysis demonstrated that even the most sensitive catchment parameters for generating runoff volume contributed to only approximately $\pm 0.07 \mathrm{~m}$ of water depth across the wetland for the entire simulation period.

The storage curve for the wetland was defined from the detailed topographic survey. The model was run for the 2013 period and compared to known surface water levels in the wetland. The wetland dries below the surface water level during summer months, and calibrating to observed surface water levels was insufficient to represent this drying. The storage curve was refined to include the subsurface using the method described above. The simulation was compared to the monitored groundwater levels to evaluate model performance. Matching of wetland hydroperiod was unsuccessful with the extended storage curve.

Based on known groundwater exchanges from the water balance, the subsurface aquifer layer was specified in the catchments, defining the wetland as the receiving node. Sensitivity was performed on the aquifer parameters and groundwater coefficients. Sensitive aquifer parameters were the initial water table elevation and soil type, both contributing to large ranges in inflows to the wetland. The groundwater inflow was calibrated using the $A 1, A 2, B 1$ and $B 2$ parameters to achieve matching in the rates and timing of wetland water level changes. The magnitudes of increases and decreases in wetland water levels were not well matched. It was hypothesized that this was due to a missing loss mechanism from the wetland.

In the absence of a surface outlet, losses from the wetland only occurred through seepage in the model, controlled by the specified Green-Ampt parameters: saturated hydraulic conductivity, suction head, and initial deficit. This seepage did not adequately represent the groundwater outflows from the wetland which are dependent on depth of water in the wetland and the gradient between wetland and downgradient groundwater system. Alternative options for representing groundwater loss from the wetland were explored:

1. A downstream orifice with a controlled flow loss dependent on area of flow and head above the orifice; and

2. A downstream catchment with negative groundwater coefficients.

Each option was investigated for its ability to meet the timing and magnitude of drawdown of levels at specific times within the wetland's hydroperiod. Option 1 was calibrated by modifying orifice area and discharge coefficient; option 2 was calibrated by modifying groundwater coefficients. Parameterization of the downstream catchment was completed using the same soils as the upstream catchment, known surface topography, and the monitored groundwater level in the downstream wells. Both options were calibrated to the observed water level in the $1 \mathrm{~m}$ groundwater wells.

In option 1, the downstream orifice was successful in matching drawdown rates in the spring and summer but could not represent the drying which occurred in the summer. Calibration was achieved by selecting an orifice area and calibrating the discharge coefficient.

In option 2, the downstream groundwater catchment was calibrated by setting $B 1=2$ and determining the $A 1$ value. The model was very sensitive to the value of $A 1$ to achieve general matching of the overall water levels and model convergence. Therefore the $A 1$ value was evaluated based on fixed $B 1$ to determine overall behaviour and convergence (OpenSWMM guidance). The $B 1$ coefficient was used to fine tune the calibration. Option 2 successfully met the timing and drawdown for the beginning of the year. However, the groundwater outflow would not converge in the later months of the simulation. The calibrated parameterization for each option is presented in Table 3.

Table 3 Calibrated model parameter summary.

\begin{tabular}{lclc}
\hline & \multicolumn{1}{c}{ Option 1: Orifice } & Option 2: Downstream Catchment \\
\hline Height $(\mathrm{m})$ & 0.045 & A1 Coefficient & $-2 \times 10^{-5}$ \\
Width $(\mathrm{m})$ & 0.045 & B1 Coefficient & 2.07 \\
Inlet offset $(\mathrm{m})$ & 0.0 & A2 Coefficient & 0.0 \\
Discharge Coefficient & 0.055 & B2 Coefficient & 0.0 \\
\hline
\end{tabular}


Figure 5 displays the results of the calibration for each option. Option 1 displayed good performance in early 2013. However, after the September rain event (approximately $110 \mathrm{~d}$ into simulation), hydroperiod matching is limited and the model performance statistics are poor. Option 2, using the downstream orifice also performs well for the first $110 \mathrm{~d}$ simulation and then the groundwater performance impacts the hydroperiod matching.

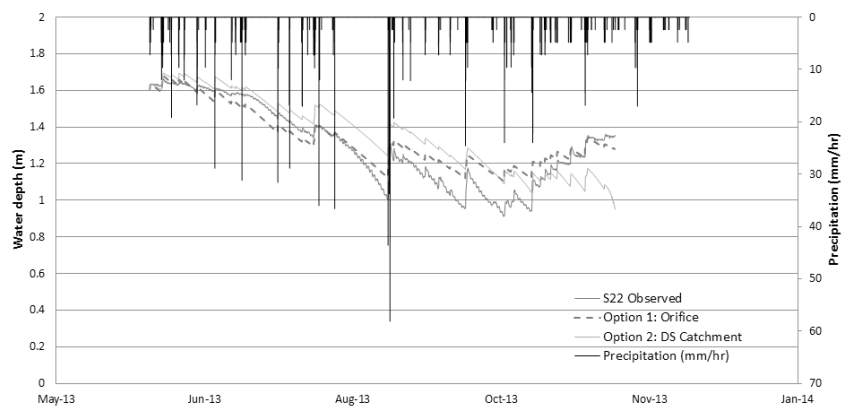

Figure 5 Calibration results for 2013.

\subsection{Model Performance}

The two options were evaluated based on the statistical outputs from PCSWMM. In the early portion of 2013 (first $110 \mathrm{~d}$ ) the downstream catchment performed very well. However in the latter part of the year the groundwater does not converge and the model does not successfully predict the known hydroperiod conditions. Calibration of the simulated orifice is more successful than the downstream catchment. It is valuable to use several different evaluation functions to assess model performance (James 2005). In 2013, the results are summarized for the first $110 \mathrm{~d}$ compared to the entire simulation period. The Nash-Sutcliffe efficiency (NSE) is a good measure of the predictive power of hydrologic models; model performance for option 1 and option 2 is very good for the first $110 \mathrm{~d}$, with NSE of 0.862 and 0.949 respectively. For this time period, additional model performance parameters have been summarized and are presented in Table 4.

Table 4 Model performance for options 1 and 2 in 2013 and 2014.

\begin{tabular}{lcccc}
\hline \multicolumn{1}{c}{ Evaluation Functions } & $\begin{array}{c}\text { Value of Perfect } \\
\text { Measure }\end{array}$ & $\begin{array}{c}2013 \\
(189 \mathrm{~d})\end{array}$ & $\begin{array}{c}2013 \\
(110 \mathrm{~d})\end{array}$ & $\begin{array}{c}2014 \\
(246 \mathrm{~d})\end{array}$ \\
\hline Nash-Sutcliffe efficiency (NSE) & 1 & -0.037 & 0.862 & -1.04 \\
Coefficient of determination ( $\left.R^{2}\right)$ & 1 & 0.306 & 0.908 & 0.11 \\
Standard error of estimate (SEE) & 0 & 0.215 & 0.0804 & 0.418 \\
Simple least squares (LSE) & 0 & 190 & 17.8 & 940 \\
Root mean square error (RMSE) & 1 & 6.22 & 3.16 & 21.9 \\
\hline & & 0 ption 2: Downstream Catchment \\
\hline Nash-Sutcliffe efficiency (NSE) & 1 & 0.794 & 0.694 & -1.01 \\
Coefficient of determination ( ${ }^{2}$ ) & 1 & 0.91 & 0.857 & 0.147 \\
Standard error of estimate (SEE) & 0 & 0.127 & 0.126 & 0.142 \\
Simple least squares (LSE) & 0 & 53.3 & 55.4 & 109 \\
Root mean square error (RMSE) & 1 & 6.03 & 6.19 & 5.19 \\
\hline
\end{tabular}

Using the calibrated models from each of the options described above, the model was validated against the 2014 data set. Figure 6 compares the 2014 simulations for each of the options used to represent outflow.

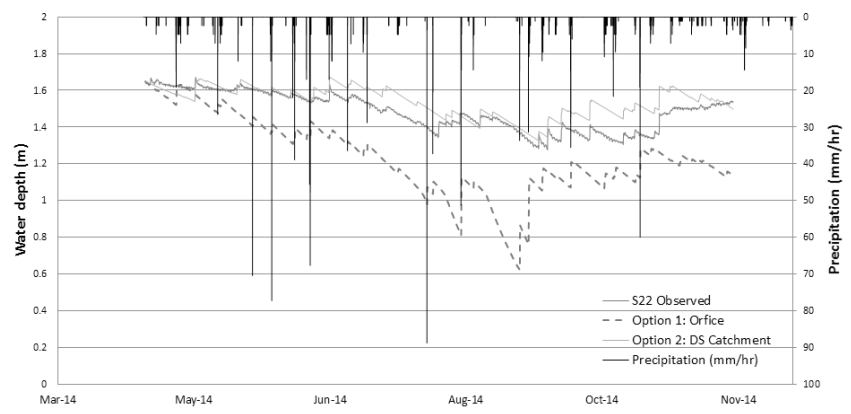

Figure 6 Validation results for 2014 data.

The wetland conditions in 2014 were not the same as 2013 as the wetland in general experienced high water levels throughout 2014. Table 5 summarizes average annual precipitation for the Toronto Buttonville four season weather station (Environment Canada 2015):

Table 5 Total annual precipitation summary.

\begin{tabular}{cc}
\hline Year & Total Annual Precipitation $(\mathrm{mm})$ \\
\hline 2011 & 982.0 \\
2012 & 898.6 \\
2013 & 1027.6 \\
2014 & 962.9 \\
\hline
\end{tabular}

Though 2013 was a wetter than average year on record, the year 2012 was drier than average, suggesting that the deeper wetland water levels in 2014 were a result of the wetter year previous. In the absence of winter precipitation data, the validation run was completed independently of the calibration run. All parameters remained unchanged with the exception of the initial water elevations in the wetland and in the downstream aquifer unit for simulation option 2. Table 4 above presents the model performance for the validation period. Option 2 performs better in 2014 than option 1. The difference in performance suggests that the factors governing orifice flow may be more sensitive to the water level in the wetland, and the larger depths in the wetland in 2014 result in larger flows. Utilizing a downstream catchment in Option 2, the model performs better indicating less sensitivity to small changes in the wetland water level.

\section{Conclusions}

Storage units can be used in PCSWMM to define a wetland and define detailed topographic information. Groundwater from the catchment subsurface can outlet to the wetland feature and simulate groundwater exchanges. In the absence of surface water outflows, the seepage parameters are insufficient to represent complex wetland groundwater losses, which occur both vertically and laterally. The inability to define groundwater flows out of a 
surface storage unit and into a downstream catchment limits the ability to calibrate the model to the wetland hydroperiods.

This study investigated two options for incorporating wetland-groundwater interactions into the PCSWMM hydrologic model framework. Including the subsurface zone in the catchment aquifer allows for the groundwater inflows to be simulated. Losses can be simulated using either a downstream catchment or an orifice loss. The orifice loss had better calibration results but validation was unsuccessful and model parameters need to be revisited. Using a downstream catchment, more errors were introduced when the model could not converge. However the validation data set performed better than the orifice option. Both options must be revisited and the model parameterization reassessed to resolve the validation inconsistencies.

\subsection{Next Steps}

Preliminary results have been used to incorporate development on the catchments and predict the impacts of development. A hypothetical development scenario with residential development of $50 \%$ impervious area has been applied to the contributing catchment areas. The main hydrologic alterations experienced from the surface system were those typical from development (i.e. increased runoff, decreased evapotranspiration and decreased infiltration). These alterations are seen in the subsurface groundwater layer (evapotranspiration and infiltration) and a decrease in groundwater output from the catchment into the wetland.

The wetland hydroperiod is being impacted by the catchment development through alterations to the surface and subsurface processes. The next step in the modeling is to separate and quantify the impacts on the wetland hydroperiod due to changes in the surface and subsurface. Low impact development practices will be incorporated in the model to target mitigation of the catchment hydrology to restore the wetland hydroperiod.

\section{References}

Acreman, M. C. and F. Miller. 2007. “Hydrologic Impact Assessment of Wetlands." In The Global Importance of Groundwater in the 21st Century: Proceedings of the International Symposium on Groundwater Sustainability, edited by S. Ragone, N. Hernandez-Mora, A. de la Hera, C. Bergkamp and J. McKay. Westerville, $\mathrm{OH}$ : National Groundwater Association Press.

Burns, M. J., T. D. Fletcher, C. J. Walsh, A. R. Ladson and B. E. Hatt. 2012. "Hydrologic Shortcomings of Conventional Urban Stormwater Management and Opportunities for Reform." Landscape and Urban Planning 105:230-40.
Carol E., E. Kruse, M. Mancuso and M. Melo. 2013. “Local and Regional Groundwater Flow Quantification in Groundwater-Dependent Wetlands." Water Resource Management 27:807-17.

Davidson, N. C. 2014. “How Much Wetland Has The World Lost? Long-Term and Recent Trends in Global Wetland Area." Marine and Freshwater Research 65 (10): 34-41.

Elliot, A. H., R. H. Spigel, I. G. Jowett, S. U. Shanker and R. P. Ibbitt. 2010. "Model Application to Assess Effects of Urbanisation and Distributed Flow Controls on Erosion Potential and Baseflow Hydraulic Habitat." Urban Water Journal 7:91-107.

Environment Canada. 2015. Monthly Climate Data for Toronto Buttonville (Station 615HMAK). Ottawa: Environment Canada. http://climate.weather.gc.ca/

Gasca, D. and D. Ross. 2009. "The Use of Wetland Water Balances to Link Hydrogeological Processes to Ecological Effects." Hydrogeology Journal 17:115-33.

Hill, A.J. and B. Durchholz. 2015. "Specific Yield Functions for Estimating Evapotranspiration from Diurnal Surface Water Cycles." Journal of the American Water Resources Association 51 (1): 123-32.

James, W. 2005. Rules for Responsible Modeling, 4th ed. Guelph: $\mathrm{CHI}$ Press.

Krause, S., A. L. Heathwaite, F. Miller, P. Hulme and A. Crowe. 2007. "Groundwater-Dependent Wetlands in the UK and Ireland: Controls, Functioning and Assessing the Likelihood of Damage from Human Activities." Water Resource Management 21:2015-25.

Mitsch, W. J., and J. G. Gosselink. 2000. Wetlands, 3rd ed. New York: John Wiley \& Sons.

Sernas Associates. 2013. Neighbourhood 18 Functional Servicing and Stormwater Management Report. Toronto: Semas Associates.

Snell, E. A. 1987. Wetland Distribution and Conversion in Southern Ontario. Ottawa: Environment Canada Inland Waters and Lands Directorate. Working Paper No.48.

TRCA (Toronto and Region Conservation Authority). 2013. Wetland Water Balance Study Preliminary Eco-hydrological Report: Existing Conditions and Study Designs for Study Wetlands. Toronto: TRCA Research and Development Section.

TRCA (Toronto and Region Conservation Authority). 2014. Seaton_Data GIS Database. Toronto:TRCA.

Wagner, I. and P. Breil. 2013. "The Role of Ecohydrology in Creating More Resilient Cities." Ecohydrology \& Hydrobiology 13:113-34. 